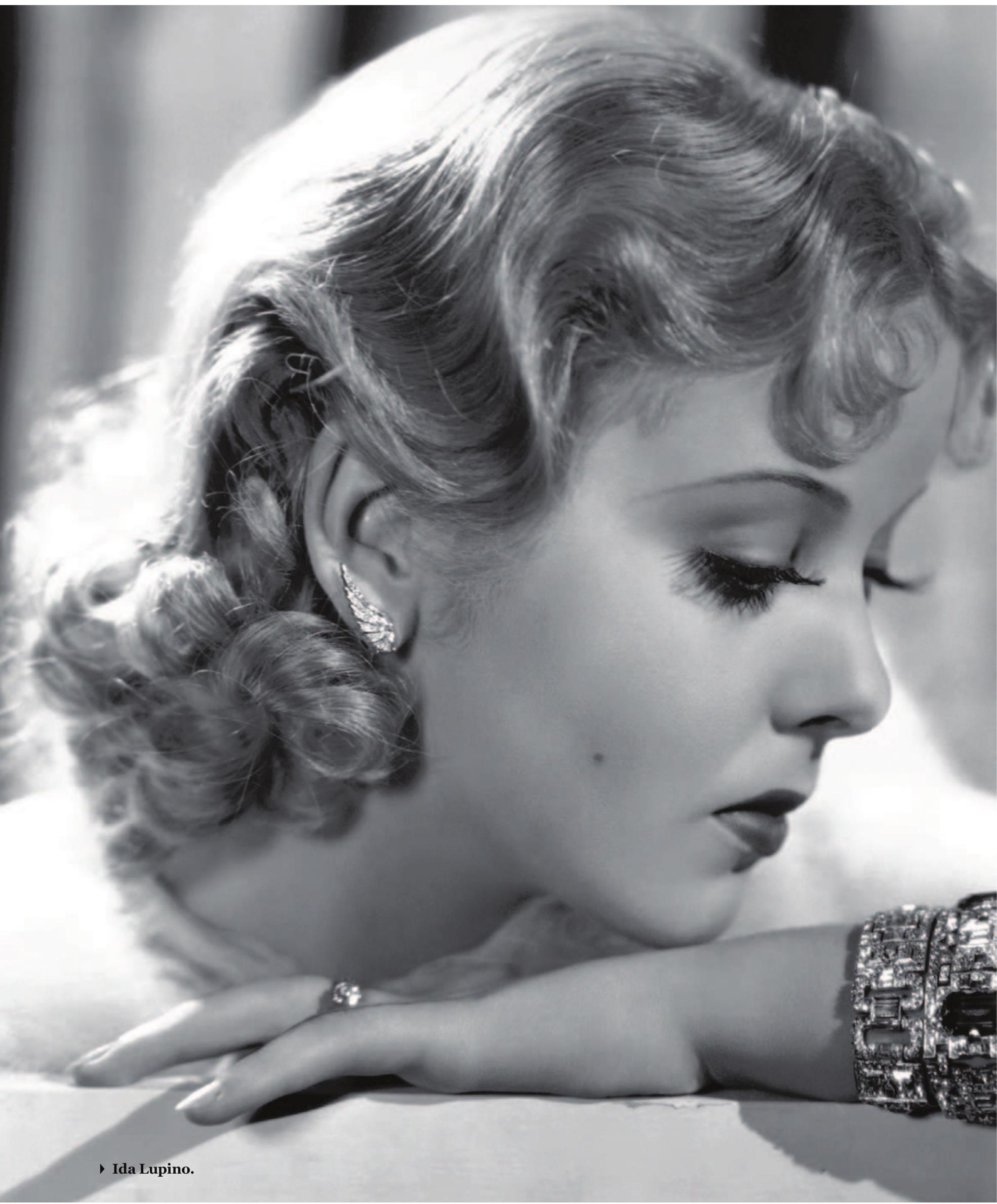

\footnotetext{
무물 


\section{CULTOS femeninos}

Tres películas de culto de tres cineastas diferentes: Ida Lupino, Doris Wishman y Sara Driver. No existe relación común entre ellas, salvo modos de producción de bajo presupuesto, pertenecer a la facción de cine independiente estadounidense lejos del canon masculino y ser mentoras de universos narrativos y expresivos fundamentales en sus diversos contextos. El film noir no fue el mismo luego de The Hitch-hiker, ni las aspiraciones lyncheanas volvieron a tener a su discípula Sleepwalk como referente de la escritura automática traducida al cine. Diario de una nudista es quizás reflejo de una época, en su ingenua modosidad a través de un softcore antológico.

\section{Mónica Delgado}

na película de culto es de por sí una obra para minorías. Y aquí no se trata de minorías exclusivamente cinéfilas, sino de la admiración, por diversas causas, promovida por diversos grupos sociales o entornos contraculturales: los melómanos otorgarán la calidad de película de culto a cintas como Tommy (1975) de Ken Russell, los punks harán lo mismo con
Sid \& Nancy (1986) de Alex Cox, mientras que los indignados del mundo harán lo propio con $V$ de Venganza (2005) de James McTeigue. Un culto por la puesta en escena rupturista, por la dirección de arte de inspiración camp o trash, por el manifiesto político que le da forma, por el humor involuntario, por la aparición del héroe porno de miembro supremo o 
por el cameo del escritor maldito y drogadicto.

No existe una fórmula exacta para que una película obtenga la fama de culto: una lanza arrojada como afrenta y que deja al azar en qué lado de la receptividad osa clavarse. Incluso hay películas muy malas, que por el solo hecho de demostrar su lado creativo a costa del buen gusto, ya se les ubica como objeto de culto, si no, recordar la serie de películas producidas por la Troma. Hay, por supuesto, directores de culto (David Lynch, John Waters, Andrzej Zulawski), pero son más usuales los casos de cineastas que dentro de su filmografía tienen estos estallidos, expresiones de "culto", y que obtuvieron este reconocimiento solo con el paso del tiempo.

Resulta paradigmático mencionar a tres cineastas que hicieron de su amor al cine un reflejo del modo de producción, pero también que gracias a esa libertad que les dio trabajar fuera de la industria, pudieran crear universos fílmicos especiales, que en algunos casos resulta también síntoma de su ser femenino en contextos masculinos: una directora de filmes softcore en plena década de los sesenta, o la traducción de la técnica de la escritura automática encarnada en un personaje femenino físicamente anodino que destaca en el extremo opuesto en medio de una sarta de estrellas pop made in Hollywood.

\section{Caso 1: Ida Lupino}

Ida Lupino fue una estrella de Hollywood que se puso detrás de la cámara, primero para dirigir películas de temática femenina, tal y como lo sugería el canon de la época (romance y drama), para luego adentrarse, desde una mirada de recursos mínimos y con énfasis en los fuera de campo y la metonimia, en la estética del cine negro. En 1953 dirigió The Hitch-hiker, una cinta de argumento sencillo pero inquietante: dos amigos que viajan en auto por la carretera recogen a un autoestopista, quien se revela como un criminal que los mantiene amenazados por kilómetros con una pistola.

The Hitch-hiker cuenta con tres actores, un auto y el desierto como espacio ominoso, que atosiga de la misma manera que el arma amena- zante. El delincuente, cuya fisonomía colabora con una tipología prejuiciosa del criminal, un estupendo William Tallman, quien ni siquiera pega el ojo para dormir, llega a la frontera con México en donde busca huir, y es hasta allí que lleva a sus dos víctimas, impotentes ante la vigilia y retos gratuitos a los que deben someterse para sobrevivir.

Lupino construye una película de culto sin una intención explícita, más bien pareciera, dejando de lado las virtudes de una película lograda, que conquistó esa denominación en la historia del cine debido a que de pronto una actriz reconocida en el medio dirigiera películas que con el paso de los años tuvieron escaso acceso, a pesar de haber sido producidas dentro de RKO.

Ida Lupino realiza un filme de setenta minutos poblado de encuadres que se apilan hacia la tensión: la amenaza no solo es el arma o el desierto, sino la cámara en un plano fijo frontal desde la luna del auto que nos hace ver los rostros de los dos secuestrados, en tanto que el criminal los abruma desde el asiento trasero con preguntas mientras los tiene en la mira de un modo omnipotente.

Si bien el final de The Hitch-hiker resulta algo flojo en comparación con el modo en que Lupino nos ha ido presentando a ese personaje antológico encarnado por Tallman, el filme es una muestra, en tiempos de pomposidad hollywoodense, que los pocos recursos pueden configurar una atmósfera inquietante, sin necesidad de femme fatales que perturben el quehacer masculino en un mundo de prófugos y perseguidos. La femme fatale está dirigiendo y haciendo películas con un ojo certero, cuidando los planos y usando las sombras como recurso de la ambigüedad.

\section{Caso 2: Doris Wishman}

Firmó sus filmes, en algunos casos, como Luigi Manicottale, Lázaro Wolk o Louis Silverman. Dirigir en la década de 1960 películas softcore, donde se muestran senos y caderas exube- rantes en situaciones demasiado correctas como días de playa o paseos diurnos, donde exhibir los genitales era impensable, no podía ser solo cosa de mujeres. Sin embargo, Doris Wishman hizo todo lo que encontró a su alcance (relaciones públicas, equipos de filmación económicos, locaciones en su propia casa, apoyo de los amigos de su esposo, y contar con actores nada profesionales para sus filmes, aunque en algunos casos se trató de estrellas porno de poca celebridad), con tal de filmar un cine para el negocio, puro exploitation, de mujeres desnudas en situaciones hoy impensables, metidas en dramaturgias inofensivas y en contextos de liberación.

Doris Wishman es una maestra del sexploitation y fuente de inspiración para la corriente del mumblecore, tendencia del cine independiente estadounidense que busca volver a sus orígenes estéticos y técnicos lejos de la fábrica "Sundance". Wishman fue una de las primeras mujeres que en la década de los sesenta se dedicó al subgénero de las nudie-cutie, que con tono casi naturalista describe la cotidianidad de las comunidades nudistas de Florida, con un estupendo e irrepetible aura camp. Ya en 1965, la cineasta se muda a Nueva York, para incursionar en aquel estilo de hacer películas que mezcla sexo explícito con violencia y sadismo: las roughie. Mujeres en busca de trabajo o de nuevas oportunidades se ven arrastradas

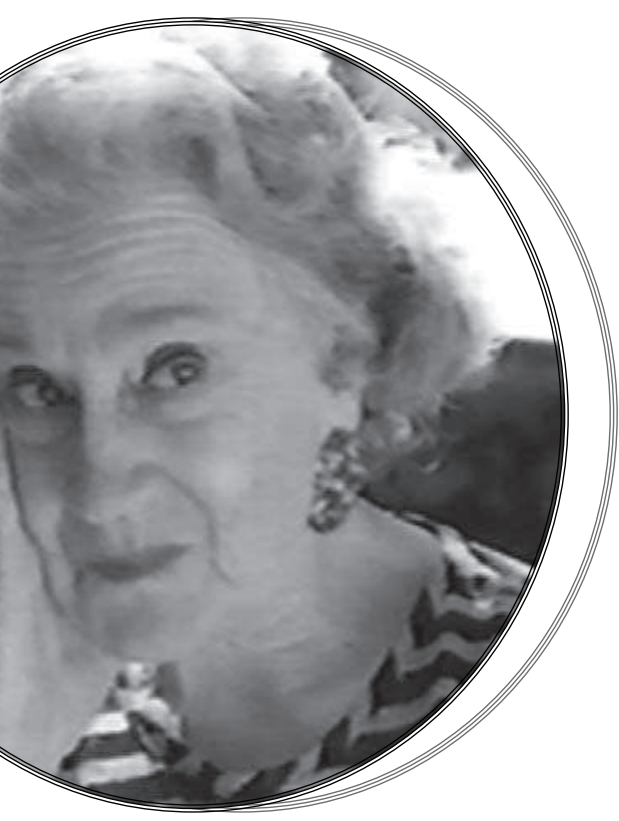


por el dinero fácil, la droga, la lujuria y el mero placer. De esta época es la maravillosa The sex perils of Paulette (1965), filmada en blanco y negro y dotada de una banda sonora de jazz y ritmos asincopados, donde se retrata a una muchacha de campo que llega a La Gran Manzana para asistir a un proceso de degeneración sexual y moral. Pero lo que atrae de este filme no es la historia de la princesa que deviene en prostituta, sino la forma en que Wishman conduce la cámara sobre los cuerpos de estos personajes de encajes y pieles desnudas, jugando con los cortes del montaje, en muchos casos abruptos, liberando de una linealidad "normal" a su puesta en escena.

Doris Wishman dirigió más de treinta películas, entre ellas Nude on the moon (1960), Bad girls go to hell (1965) y Double agent 73 (1974). Y si bien ella posee todas las "características" para ser una directora de culto dentro del cine independiente estadounidense, su filme Diario de una nudista (1963) es un ejercicio que contiene ingenuidad, curiosidad y sentido de voyerismo restringido plasmado con ojo que cuida la exhibición de genitales, siendo una experiencia que roza lo bizarro. Una periodista se resiste a ser enviada como reportera a una comunidad nudista, sin embargo, tras una conversación casi mecánica con su editor, es motivada a vivir la situación, viéndose tentada a seguir manteniendo ese estilo de vida más allá del reportaje encomendado.

Wishman sigue a su protagonista, con ojo cuasi documental, mientras los habitantes de esta colina juegan voleybol, nadan, toman sol o conversan en el desayuno. Un desfile de senos de todos los tamaños, mujeres que colocan sombreros, toallas, periódicos, pelotas, bolsos a la altura del vientre, evitando así, mientras corren o caminan, mostrar a la cámara sus partes íntimas. Hay una intención por dar materialización a esa crónica periodística, tomando distancia y al enfatizar planos que en muchos casos logran la abstracción.

Es inevitable que Diario de una nudista, que intenta ser un relato personal de esta visita, remita al espíritu camp muy de los sesenta, tanto por la moda como por los espacios filmados. Diálogos de actuaciones pobres, montaje en algunos casos abruptos, planos panorámicos, y un desenlace kitsch para la hora de metraje dedicada a detenerse en decenas de cuerpos sin ropa.

Wishman filma desde el bajo presupuesto, desde las posibilidades de un sexploitation sugerente, donde el coito no existe en este mundo bucólico, solo dando lugar a la mirada voyeur, como la de un invitado castigado en este grupo libre de pecado. Por eso sorprende este inicio sublimado de Wishman en este tipo de películas, antes de entrar de lleno a las roughie de la otra etapa de su carrera, donde sí es más explícito el sexo y el mundo podrido. Wishman perdiendo poco a poco su virginidad.

\section{Caso 3: Sara Driver}

Productora y pareja de Jim Jarmusch, Sara Driver es una cineasta poco reconocida, poseedora de una breve filmografía que va desde el documental de una ciudad como Nueva York hasta la experimención con lo surreal; entre dos polos. Sleepwalk (1986), como Diario de una nudista de Doris Wishman, responde ineludiblemente a una necesidad de su tiempo: en ese caso, captar la esencia del pop en una ciudad emblemática y subvertir con ludismo la efervescencia de un mundillo, visto a la luz del tiempo, típicamente ochentoso. Ambientada en Chinatown, Suzanne Fletcher encarna a Nikki, una mecanógrafa que es captada por un tal Dr. Gou para traducir un antiguo manuscrito chino, que termina estando maldito al modificar momentos de su vida.

Driver usa intertítulos, textos sobre las imágenes, yuxtapone sueños a lo real, pero también llena su filme de indicios de estar contemplando un mundo paralelo, al estilo Lynch. Lo intertextual se apodera del nonsense, en diálogos, en tomas de una ciudad de habitantes enrarecidos. En Sleepwalk gana el azar: pareciera que no hay un argumento claro, que oscila entre el pastiche y el cine negro, entre la comedia, la ciencia ficción y el drama pop.
Sleepwalk comienza como si fuera una cinta de misterio, un objeto o persona al que hallar, sin embargo, esta línea pierde sentido al encontrarnos imbuidos en la vida de Nikki y el secuestro de su hijo chino. Y la trama se complejiza llenándose de intertextos, que relacionan a los personajes bajo códigos trillados, todo bajo una atmósfera surreal, siguiendo una ruta que imita la escritura automática,

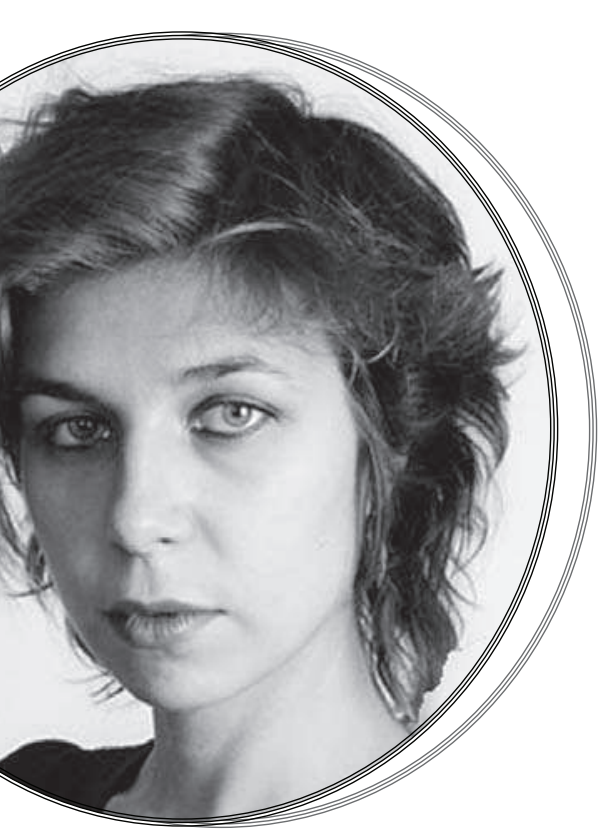

puesto que apariciones, situaciones o diálogos inesperados cobran importancia en este ruptura constante de estilos. Una fantasía de rasgos insólitos, con un uso del color, sobre todo de rojos (en objetos específicos: vestido, labios, teléfono, cabellos), que exacerban esa idea de que estamos asistiendo a un relato poco cuerdo, pero que en sus interferencias y yuxtaposiciones se encuentra una ilación sobre ese trasfondo anodino que es la ciudad de Nueva York.

Este primer largometraje de Sara Driver es una apuesta de exacerbación visual, que deja de lado el relato lineal narrativamente hablando, ya que en su puesta en escena se valora el logro de atmósferas donde reina el sinsentido, el fantástico, como pocas veces ha mostrado el cine independiente estadounidense.

Tres películas de culto que, sin exagerar, han pasado a convertirse en objeto de devoción precisamente porque han sido dirigidas por mujeres, es decir, por el hecho de haber sido rea- 


\section{Actores y actrices de culto (III): Traci Lords}

Miradas cándidas. Gemidos ensordecedores. Movimientos lascivos. Poses gimnásticas. Todos aquellos juegos sensoriales se concentraron en el cuerpo menudo pero de prominentes curvas de Nora Louise Kuzma. Con el nombre artístico de Traci Lords, se convirtió en una de las mayores fantasías lúbricas de los consumidores de videos porno en los años ochenta. Pero aquella carrera en la industria de cine para adultos tuvo un final inesperado. Autoridades norteamericanas descubrieron que la Lords usaba documentación falsa para aparentar que era mayor de edad, cuando en realidad participó en aquellas películas cuando solo tenía entre 15 y 17 años. El escándalo llevó a muchos de sus compañeros y empleadores a tener una breve estadía en la cárcel; sin embargo, su terrible travesura, casi adolescente, le permitió hacerse de un espacio en el mainstream cinematográfico.

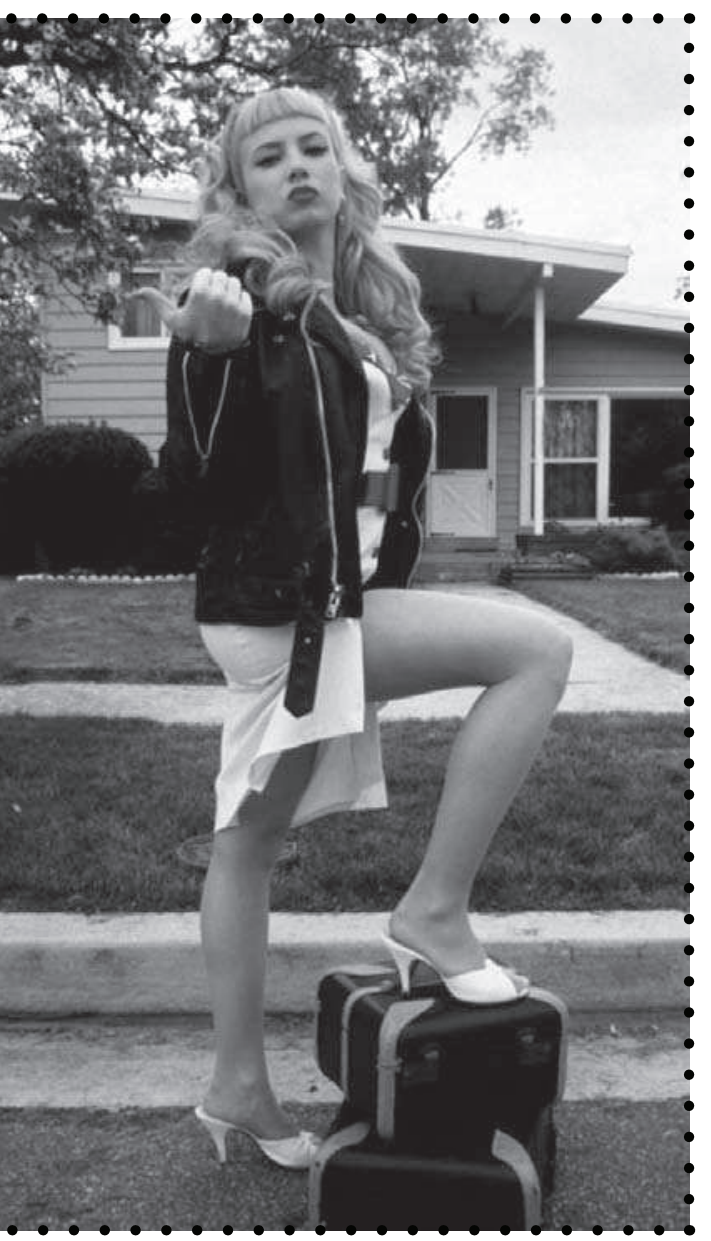

El mítico productor Roger Corman le dio un papel protagónico en el remake de un filme de ciencia ficción suyo, Not of this earth (1988) de Jim Wynorski. Su participación en aquella cinta la catapultó en su momento como la nueva reina del cine de serie B. Además, la película de alguna manera estableció algunos de los rasgos que tendrían futuros personajes de Traci Lords, que la convertían en la encarnación de una mujer provocadora, vamp, de aura coqueta y sensual. Así desfilan desde el personaje chillón de Wanda en Cry-Baby (1990) de John Waters, pasando por la sexy vampiresa que va a una sanguinaria fiesta electrónica en Blade (1998), hasta la mujer con reminiscencias de guerrera amazónica de Princess of Mars (2009), una cinta comercializada directamente en video y dirigida por Mark Atkins.

Muchas de las películas más exitosas en las que ha participado Traci Lords, que ahora tiene 43 años, la colocan en personajes secundarios o de breve aparición. Sin embargo, ella ha conseguido a lo largo de su carrera un pequeño grupo de fans lo suficientemente fieles a su figura como para verla por solo unos minutos o en cintas de acabado camp. Hace un tiempo la pudimos ver en la cartelera peruana protagonizando una película de terror de mediana calidad llamada El entierro (2006), de James K. Jones. Sin embargo, uno de los personajes más carismáticos a los que ha dado vida en los últimos años es aquel que interpreta en Zack y Miri hacen una porno (2008) de Kevin Smith. En aquel filme, da vida a una actriz porno que tiene el extraño talento de formar burbujas con el soplido de su órgano genital. Tal vez esa sea la mejor metáfora que el cine haya podido hacer de la insólita carrera de Traci Lords, quien supo juguetear con su imagen de Lolita con triple equis para encontrar una entrada hacia la adultez en la pantalla.

Cabrejo
Tres películas

de culto que

han pasado a

convertirse en

objeto de devoción

por el hecho

de haber sido

realizadas por

directoras en el

contexto del cine

independiente, sin

ser radicalmente

experimentales

o insólitas en su

aspecto formal.

lizadas por directoras en el contexto del cine independiente, sin ser radicalmente experimentales o insólitas en su aspecto formal, enfatizando más bien sus estéticas en tipos de cine de hegemonía masculina tanto desde la dirección como del lado del espectador: softcore y hardcore dirigida por una esposa dedicada que encontró en este tipo de cine un vehículo expresivo sin afán de hacer declaraciones feministas o de alguna índole de género, sino siguiendo al pie de la letra el canon de representación del cine porno. Por otro lado, Sleepwalk comparada con Ghost dog (1999) del marido Jim Jarmusch, como si se tratara de un asunto familiar y de herencia por convivencia. Lo mismo sucede con The hitch-hiker (de personajes hombres de un cine negro para hombres) que pasa a la posteridad porque una famosa actriz decide tomar la cámara y proponer una historia apostando por los recursos del género. De todas maneras, tres cintas importantes que sin tener de modo explícito una mirada desde lo femenino, apuestan por darle un lugar a la dirección de cine hecha por mujeres como una oportunidad de dejar en claro que lo creativo no tiene barreras. 